\title{
Gutfile \\ Elemental diet in the treatment of orofacial Crohn's disease
}

\section{HISTORY}

A 12 year old boy presented via his orthodontist with a three month history of facial swelling and a one year history of intermittent diarrhoea. Examination revealed a pale boy with asymmetrical thickening of his cheeks, a buccal mucosal fold on the left, and friable mucosa on the right. Investigations revealed a mild hypochromic microcytic anaemia and raised inflammatory markers.

\section{DIAGNOSTIC PROCEDURES}

An oral biopsy showed occasional granulomata and a mixed inflammatory infiltrate with negative fungal stains consistent with a diagnosis of orofacial granulomatosis. ${ }^{99} \mathrm{Tc}^{\mathrm{m}}$-HMPAO leucocyte scintigraphy showed grade 3 white cell activity in the terminal ileum and caecum and grade 2 activity in the ascending colon and rectum. At colonoscopy, patchy aphthous ulceration was seen from the rectum to the caecum, more pronounced proximally, and biopsies revealed granulomatous inflammation consistent with a clinical diagnosis of Crohn's disease.

\section{INTERVENTION/OUTCOME}

Elemental diet was commenced resulting in a dramatic improvement within two days. Two relapses have responded to further treatment with elemental diet.

\section{DISCUSSION}

Orofacial granulomatosis is a condition in which granulomatous lesions are found in the mouth and face. It may be idiopathic or part of MelkerssonRosenthal syndrome or cheilitis granulomatosa, and may occur in association with a number of systemic diseases (Crohn's disease, sarcoidosis, and Mycobacterium tuberculosis infection). ${ }^{1}$ Approximately $10 \%$ of cases of orofacial granulomatosis are due to Crohn's disease although rarely if blood haematinics and inflammatory markers are normal.

Orofacial Crohn's disease can present at a wide range of ages (6-78 years) with a prevalence as high as $27 \%$ in paediatric Crohn's disease populations. The clinical features include labial swelling $(66 \%)$, mucosal cobblestoning $(38 \%)$, linear ulcers $(38 \%)$, localised swellings $(17 \%)$, and mucosal tags $(7 \%)^{2}$ Symptoms include pain, and difficulty eating and speaking but presentation may be cosmetic. $^{2}$ Biopsies frequently show granulomas with oedema and an inflammatory infiltrate. There is no correlation between activity of orofacial and intestinal disease in Crohn's disease, and the onset of orofacial disease can occur prior to, concurrently with, or following the onset of gastrointestinal disease. ${ }^{2}$

Various treatments (treatment of chronic dental infections, corticosteroids, sulphasalazine, cotrimoxazole, metronidazole, ${ }^{1}$ azathioprine, cyclosporin, and infliximab ${ }^{3}$ ) have been utilised in orofacial granulomatosis with mixed success. A role for food intolerance in the aetiology of orofacial granulomatosis has been suggested ${ }^{4}$ although response to elimination diets have been variable. ${ }^{25}$ One case with documented intolerance to food colourings and monosodium glutamate improved with elemental diet. $^{4}$

Elemental diets are liquid feeds containing protein as amino acids, carbohydrate as maltodextrins and sugar, fat as small quantities of defined oils, plus vitamins and minerals. They have been used in the treatment of active Crohn's disease, particularly in children and adolescents in whom the adverse effects of corticosteroids on growth should be avoided if possible. Unfortunately, unpalatability can make non-compliance rates high.

Elemental diet should be considered as an option in this difficult to treat condition, particularly in children when corticosteroids should be avoided if possible.

E A B Cameron, S J Middleton,

Department of Gastroenterology, Addenbrooke's Hospital, Cambridge, UK

Correspondence to: Dr S J Middleton, Department of Gastroenterology, Unit E7, Box 201 a, Addenbrooke's Hospital, Cambridge CB2 2QQ, UK; stephen.middleton@ addenbrookes.nhs.uk

\section{REFERENCES}

1 Wiesenfeld D, Ferguson MM, Mitchell DN, et al. Oro-facial granulomatosis-a clinical and pathological analysis. QJ Med 1985;213:101-13.

2 Williams AJK, Wray D, Ferguson A. The clinical entity of orofacial Crohn's disease. $Q$ J Med 1991;289:451-8.

3 Mahadevan U, Sandborn WJ. Infliximab for the treatment of orofacial Crohn's disease. Inflamm Bowel Dis 2001;7:38-42.

4 Sweatman MC, Tasker R, Warner JO, et al. Oro-facial granulomatosis. Response to elemental diet and provocation by food additives. Clin Allergy 1986;16:331-8.

5 Sainsbury CPQ, Dodge JA, Walker DM. Orofacial granulomatosis in childhood. $\mathrm{Br}$ Dent J 1987:163:154-7. 